\title{
Linking social capacities and risk communication in Europe: a gap between theory and practice?
}

\author{
Corina Höppner • Rebecca Whittle • Michael Bründl • Matthias Buchecker
}

Received: 19 May 2011/Accepted: 30 July 2012/Published online: 29 August 2012

(C) The Author(s) 2012. This article is published with open access at Springerlink.com

\begin{abstract}
Although both improved risk communication and the building of social capacities have been advocated as vital ways to increase societies' resilience towards natural hazards across the world, the literature has rarely examined the ways in which these two concepts may integrate in theory and practice. This paper is an attempt to address this gap in a European context. It begins with a conceptual discussion that unites the literature on risk communication with the literature on social capacity building. We then use the insights from this discussion as a basis to conduct a review of 60 risk communication practices from across Europe. This review indicates a gap between theory and practice because, whilst the literature highlights the importance of integrated and coordinated communication campaigns featuring both a one-way transfer and a two-way dialogue between the public, stakeholders and decision-makers, the majority of the communication practices reviewed here appear to be relatively disparate initiatives that rely on one-way forms of communication. On the basis of these findings, we conclude by making some recommendations for the way in which such practices could be improved in order to be more supportive of social capacities across Europe.
\end{abstract}

Keywords Risk communication · Capacity building · Participation · Warning · Prevention

Electronic supplementary material The online version of this article (doi:10.1007/s11069-012-0356-5) contains supplementary material, which is available to authorized users.

C. Höppner $(\bowtie) \cdot$ M. Bründl $\cdot$ M. Buchecker

WSL Swiss Federal Institute for Forest, Snow and Landscape Research, Zürcherstrasse 111, 8903

Birmensdorf, Switzerland

e-mail: corina.hoeppner@ebp.ch

C. Höppner

Ernst Basler + Partner, Mühlebachstrasse 11, 8032 Zürich, Switzerland

R. Whittle

Lancaster Environment Centre, Lancaster University, Lancaster LA1 4YQ, UK 


\section{Introduction}

Communication on natural hazard ${ }^{1}$ risks has grown to be an important strand of risk research and management. In Europe, communication on risks has been enshrined as a fiduciary responsibility of official bodies in a number of policy documents such as the Seveso II Directive (Directive 96/82/EC), the Water Framework Directive (Directive 2000/60/EC) and the European Union Directive on the Assessment and Management of Floods (Directive 2007/60/EC).

In theory and practice, risk communication may serve a range of objectives, with awareness raising, knowledge transfer and the provision of behavioural advice figuring most prominently across the risk literature. However, in this paper, we argue that the existence of such knowledge on natural hazards-in terms of the risks involved, how to prevent, prepare for and behave during hazard events, and how to recover afterwards-can also be understood as a form of social capacity.

Social capacity building has been identified and promoted as a critical way to increase societies' resilience towards natural hazards (e.g. Adger et al. 2005). Social capacities are abilities, skills and competences that help people to better prepare for, respond to, recover from or adapt to the negative impacts of natural hazard events (Kuhlicke et al. 2010). The Hyogo Framework for Action 2005-2015, for instance, stipulates that resources should be allocated for 'awareness-raising initiatives and for capacity-development measures' (UN/ ISDR 2006, p 5) to assist individuals and organisations in dealing with the increasing risk and occurrence of natural hazards - particularly those which are weather-related. However, the links between social capacity building and risk communication are not generally discussed in the natural hazards literature. This is problematic given that both social capacity building and risk communication are now understood to be key objectives in building resilience to natural hazards. For example, risk governance has been argued to provide the framework for social capacity building with risk communication being conceptualised as one key process through which social capacities are developed (Kuhlicke et al. 2011).

We argue that risk communication may help to create an environment that is conducive for the building of social capacities at the level of individuals, communities and riskmanaging organisations (also see Kuhlicke and Steinführer 2010) in relation to natural hazards. However, our review of a diversity of risk communication practices across Europe indicates that, as yet, knowledge on which forms of communication are suitable to targetspecific social capacities is rarely translated into action on the ground. Furthermore, as Kuhlicke and Steinführer (2010) observe, whilst there is a long-standing call for capacity building in the context of developing countries, Europe has only recently acknowledged such links in relation to natural hazards. This paper aims to explore the interrelationship between risk communication and social capacity building within the research literature and natural hazards management to derive recommendations for a more efficient risk communication.

We draw on work carried out as part of CapHaz-Net (www.caphaz-net.org), an FP7funded research project that aims to create a European-wide network of social scientists

\footnotetext{
1 We define natural hazards as a general term for all gravitational, meteorological and seismic processes that might cause harm to people and material assets. Natural hazard risks denote risks caused by natural hazards, either as discrete hazards (e.g. single avalanche) or as multi-hazards (e.g. debris flow induced by landslide). Risks that arise from technical facilities affected by natural hazards (e.g. chemical accidents due to earthquakes) are excluded from this paper.
} 
and practitioners to explore the social dimensions of natural hazards. Specifically, CapHazNet aims to better understand the relationship between social capacity building and wellestablished fields of research such as risk perception, social vulnerability, risk governance and risk communication.

The paper is organised as follows. We begin by exploring the relationships between social capacities and the different purposes and theoretical models of risk communication. Following the overall approach of CapHaz-Net, we focus on communication taking place between decision-makers, stakeholders and the public. Subsequently, we describe the methodology of our research and present a review of 60 natural hazard-related risk communication practices in Europe. We follow this review by highlighting current challenges and conclude with recommendations for communication strategies and future research.

\section{The current state of risk communication}

Risk communication is becoming an increasingly important activity in response to the changing nature of risk governance. Today, natural hazard management is moving beyond attempts to simply find solutions or provide emergency responses towards more integrated models that stress prevention and preparation (Walker et al. 2010a; Mileti 1999). Accordingly, communication must serve multiple purposes and functions throughout the hazard cycle (i.e. prevention/preparation, warning, emergency response and recovery) and ideally span all successive phases of risk management, from the framing or assessment of the risk situation to the implementation and evaluation of measures (Renn 2005). This shift brings new challenges for communication as it must be tailored to a variety of purposes and actors (state and non-state agencies, organisations, stakeholder groups, the public) at different spatial scales. A focus on prevention also underlines the need for capacity at the level of individuals, communities and organisations to proactively prepare them for hazardous events. Moreover, different hazards may require different risk communication goals and tools (e.g. Höppner et al. 2010).

Risk communication is thus an increasingly complex activity which is moving beyond the one-way provision of information and the building of trust in risk-managing bodies towards a two-way exchange of knowledge and views throughout the risk cycle (see Fig. 1).

Having considered general trends and approaches to risk communication, we now introduce the concept of social capacity and explore the ways in which different forms of communication might contribute to a range of social capacity types.

\section{Linking social capacities and risk communication}

Social capacities refer to the abilities, skills and internal resources of an individual, group or organisation to successfully anticipate and respond to external stressors such as hazardous events (also see Kuhlicke and Steinführer 2010). They can thus be distinguished from what others have labelled 'physical/material' capacities, such as the creation of floodresistant buildings, or economic capacities, such as having the financial means to rebuild infrastructures (Anderson and Woodrow 1989; Bollin and Hidajat 2006). Social capacity is multi-faceted and, based on the literature and discussions within CapHaz-Net (e.g. Anderson and Woodrow 1989; Fichter et al. 2004; Powell and Colin 2009; Gupta et al. 


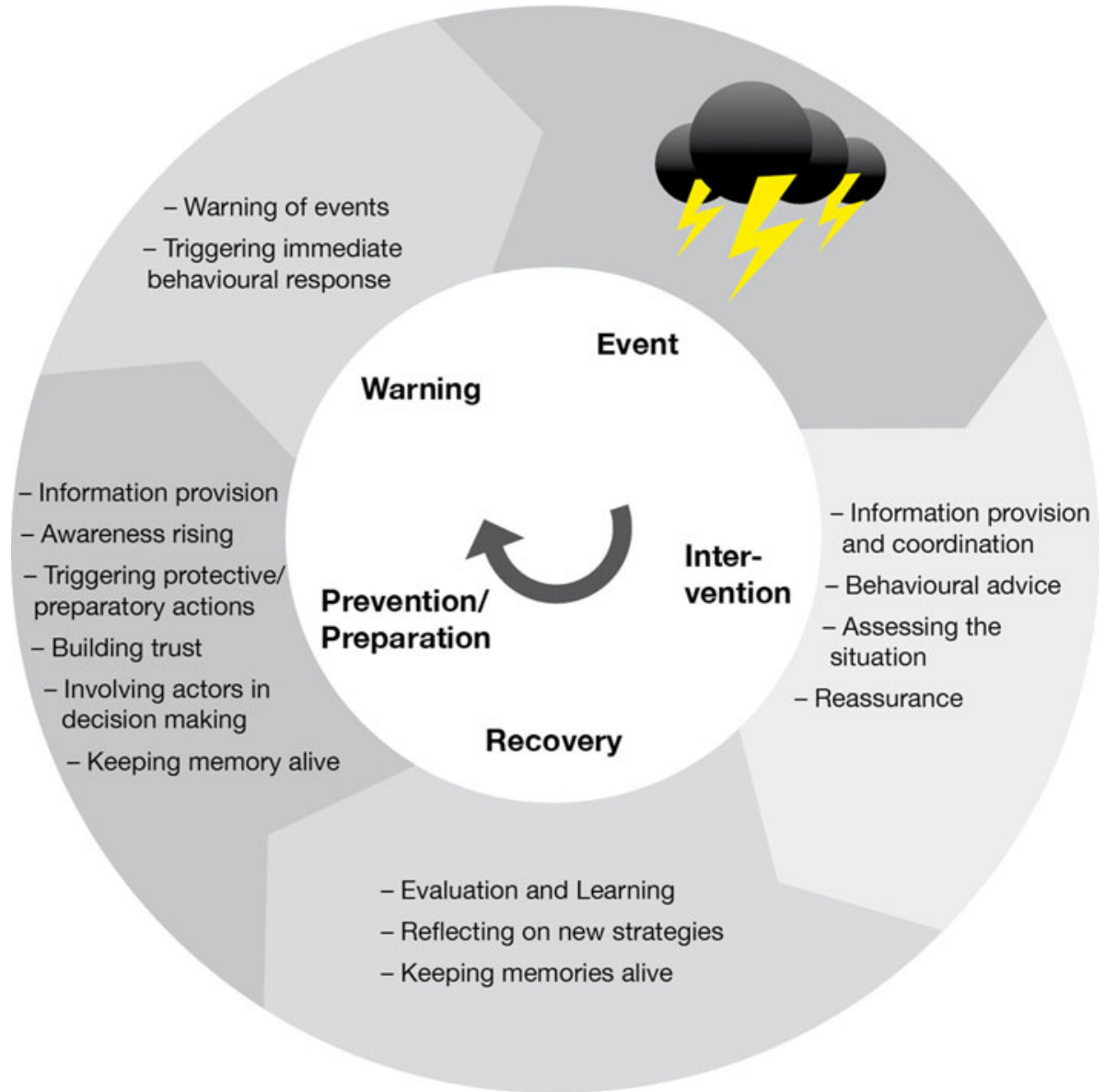

Fig. 1 Objectives of risk communication before, during and after a hazard event (adapted and extended from the Swiss National Platform for Natural Hazards PLANAT, see www.planat.ch)

2010), we suggest subdividing the concept further into four key elements: knowledge capacities, attitudinal/motivational capacities, social/organisational capacities and emotional/psychological capacities (see Table 1 for description of social capacity types).

\subsection{Evidence for the effects of communication on social capacities}

There are many studies debating the merits of communication and trying to establish which formats of communication may be most effective (e.g. Faulkner and Ball 2007; FernándezBilbao and Twigger-Ross 2009; Kashefi and Walker 2009; Bier 2001). Based on this broad body of work, we argue that risk communication is one pivotal way to build social capacities within a society. In the following, we summarise the ways in which communication may impact on the four social capacity types listed in Table 1. 
Table 1 Types of social capacity building (adapted and extended from Kuhlicke and Steinführer 2010; Höppner et al. 2010)

\begin{tabular}{|c|c|}
\hline Types of social capacities & Description \\
\hline Knowledge capacities & $\begin{array}{l}\text { Knowledge about the hazard and the risk } \\
\text { Knowledge about how to prepare for, cope with and recover from hazardous } \\
\text { events } \\
\text { Knowledge about other actors involved in the handling of hazards } \\
\text { Knowledge of formal institutions such as legal frameworks and laws } \\
\text { Knowledge about values, norms and beliefs of different actors }\end{array}$ \\
\hline $\begin{array}{l}\text { Attitudinal/motivational } \\
\text { capacities }\end{array}$ & $\begin{array}{l}\text { Awareness of hazards and risks } \\
\text { Motivation to prepare for, prevent and recover from the adverse impacts of } \\
\text { natural hazards } \\
\text { Willingness to learn about risks and hazards and to comply with advice } \\
\text { Self-efficacy beliefs, that is, 'people's judgements of their capabilities to } \\
\text { organise and to execute courses of action' (Bandura 1986, p 391) that make } \\
\text { them less vulnerable to the adverse impacts of natural hazard events }\end{array}$ \\
\hline $\begin{array}{l}\text { Social/organisational } \\
\text { capacities }\end{array}$ & $\begin{array}{l}\text { Communication skills and ability to establish and maintain trustful relationships } \\
\text { Organisation skills } \\
\text { Networking and cooperation abilities }\end{array}$ \\
\hline $\begin{array}{l}\text { Emotional } / \text { mental } \\
\text { capacities }\end{array}$ & $\begin{array}{l}\text { Psychological resources and abilities that are needed to cope with stress or } \\
\text { anxiety and to prevent trauma, for example, stress management skills, ability } \\
\text { to regulate emotions } \\
\text { People's ability to self-assess the impacts of hazardous events on their mental } \\
\text { and emotional health and their need for support }\end{array}$ \\
\hline
\end{tabular}

\subsubsection{Knowledge and attitudinal/motivational capacities}

Many communication efforts seek to increase people's knowledge and awareness about various hazards and, ultimately, get them to alter their behaviour before, during and after a hazardous event. Research on which formats of communication (quantitative/qualitative, printed/computer-mediated/face-to-face, etc.) are 'best' at building up knowledge have produced ambiguous results and mainly reveal that the preferred formats depend on the purpose of the communication effort (Bier 2001). For example, Moser (2010, p 41) summarises that 'face-to-face communication tends to be more persuasive and impactful' in changing attitudes and behaviour than mass-media(ted) communication. Older people in the United Kingdom also reacted more positively to a knock on their door by flood wardens than to some flood warning technologies (e.g. dial-and listen flood warning services), which they found less user-friendly (Parker et al. 2009).

At least as relevant as the format is the content of the communicated information. In the context of climate change, Spence and Pidgeon (2010) have recently shown that different framings (e.g. loss or fear frames vs. gain frames) might be needed for promoting the acceptance of mitigation measures on one hand and triggering specific behaviours on the other. Whilst gain-framed messages (i.e. messages that focus on the positive consequences of action) tend to be more effective in promoting acceptance of climate change mitigation measures, loss frames can be more effective in motivating people to seek further information on their personal vulnerability, for example, whether their homes are at risk from flooding. Lakoff (2010, p 79) argues that good communicators need to combine frames and messages 'that are needed in the long run, as well as those needed to battle the right-on issues of the day'. One of the lessons for risk communication on natural hazards is that the effectiveness of shortterm communication frames, such as immediate warning, may depend on the prior effectiveness of long-term frames aimed at better preparing people for future events. 
Other authors argue that risk communication reaches the target groups best if it addresses relevant aspects of their mental models of risk situations, their personal problem frames (Kolkman et al. 2007; Rowan 1994) and salient cultural frames (Uskul and Oysermann 2010). Similarly, Manojlovic and Pasche (2008) show that appealing to personal emotions and experiences is key to raising people's interest in risk-related information. Assessing what the intended target audience knows, believes and values is therefore a key requirement for designing effective risk communication messages (Bier 2001).

Meanwhile, dialogical forms of risk communication appear to be able to change attitudes towards planning measures. For example, the evaluation of a consensus-building process in the context of a Swiss river restoration project revealed that the process not only resulted in stronger support for the negotiated project, but also of river restoration projects in general (Buchecker 2008). However, a number of authors (Buchecker et al. 2010; Heath and Palenchar 2000; Höppner et al. 2005, 2007) argue that, for communication to actually develop impact, regular efforts are needed, rather than one-off campaigns.

However, communication is not the only factor. For example, Weiss et al. (2010) stress that specific emergency training is needed to help people transfer their knowledge and motivation into action.

\subsubsection{Social/organisational capacities}

There are few systematic evaluations of the effects of communication on social networks and people's capacities to establish trustful relationships. The majority of studies focus on short-term effects, so there is considerable uncertainty about the longer-term persistence of these effects (Buchecker et al. 2010).

Across research fields, it is widely held that communication is a way to build or regain people's trust in decision-makers or other stakeholder groups (Kasperson et al. 1992; Slovic 1993; Beierle and Konisky 2000). However, it is also often assumed that one-way communication can achieve trust building only to a very limited degree (Parker et al. 2007) and empirical studies have confirmed this, particularly in terms of rebuilding trust (Conchie and Burns 2008).

Quasi-experimental studies in the context of landscape planning also revealed that, in short-term, two-way communications too, trust in the organising institutions only increased if the processes were high quality and well-legitimised (Buchecker et al. 2010; Höppner et al. 2007). There is also some evidence that two-way communication contributes to other aspects of social capital and relationships. Long-term monitoring of a watershed partnership in the United States appeared to show that mutual understanding amongst stakeholders and the quality of their relationships gradually increased and fully developed only after a period of 4 years (Leach et al. 2002).

In conclusion, then, the literature shows limited but consistent evidence that risk communication-particularly in its two-way format-has positive effects on people's ability to establish and maintain trustful relationships. Two-way communication furthermore develops communication skills that are vital for networking and cooperation amongst individuals and organisations.

\subsubsection{Emotional/mental capacities}

There is growing evidence for the adverse psychological impact of natural hazards on human health. Studies show that short-term effects such as apathy, stress and fatigue can result in long-term post-traumatic stress disorders (e.g. Neria et al. 2008), depression and 
anxiety. People may also feel isolated and their economic productivity may be compromised (Cook et al. 2007). It is argued that such psychological effects can hinder quick recovery from hazardous events and also reduce people's ability to mobilise and to enact their knowledge on how to behave in emergencies and times of crisis (e.g. DeSalvo et al. 2007). Experiences from climate change communicators suggest that building positive emotional capacities requires a language that is optimistic and energetic rather than provoking fear and powerlessness (Ereaut and Segnit 2006; Futerra 2010).

Within the hazards field too, positive emotional and mental capacities such as agency, hope, optimism, stress resistance and the ability to regulate emotions (Zautra et al. 2008; Neria et al. 2008) are thought to be vital for increasing psychological robustness before a hazard hits. Such capacities ideally reduce the frequency and severity of the adverse effects on health and support task-related responses rather than emotional responses to stressful events (Neria et al. 2008). Basic skills of stress management or specific coaching programmes at the community level can be one way to better prepare people for psychologically demanding situations.

However, research also shows that these resources of psychological resilience are strongly entangled with the other three capacity types, leading to different framings of the problem. For example, social relationships and networks are seen as vital for people's emotional stability and mental robustness as they can produce positive feelings of social connectedness and support (Berkman and Glass 2000; Rowe and Liddle 2008), whilst feelings of personal control support positive emotions and might counteract apathy and increase stress resistance (Pearlin and Schooler 1978; Reich and Zautra 1990). One way to stimulate people's sense of control and reduce anxiety is to provide them with knowledge on how to act in critical situations. Building knowledge on the negative psychological impacts of such situations enables people to read the signs of such changes in themselves and others.

Yet, research on people's long-term recovery from hazards also urges extreme caution around considering the 'mental health' impacts of a disaster in isolation from the many other factors at work in the situation (Whittle et al. 2010, Walker et al. 2010b, Mort et al. 2004). These studies show that the best way of helping people with the mental and emotional impacts of the disaster is to help them solve the practical problems that are preventing them from getting their lives and homes back on track. Such help may, of course, include the development of more effective forms of communication-particularly as a key stressor for many people is not being able to have a regular and productive dialogue with the organisations who are dealing with their case.

Consequently, whilst the number of studies grows, research on how and whether communication can contribute to emotional and mental capacities is still very limited and there is disagreement amongst researchers on this matter.

The foregoing discussion has provided an initial exploration of the links between risk communication and the four kinds of social capacities highlighted in Table 1 . We have shown that, depending on the specific purpose of communication, different formats of communication (quantitative/qualitative, printed/computer-mediated/face-to-face, etc.) and frames (e.g. loss or fear frames vs. gain frames) can be most effective in increasing people's knowledge and their motivation to act. Dialogical and long-term communication also appear to be particularly suited to influencing people's attitudes towards planning measures and increasing their social/organisational and emotional/mental capacities. We now draw on this brief review to discuss how different approaches to risk communication in the field of natural hazards might create an environment that is conducive to the development of social capacities. 
3.2 Theoretical approaches to the communication of natural hazards and their links to social capacities

A burgeoning literature has advanced an array of conceptual approaches to risk communication, each stemming from a somewhat different disciplinary background and highlighting different aspects of, and implications or guidelines for, communication practice (for an overview see Lundgren and McMakin 2009).

In the field of natural hazards, we find that communication models have mainly been developed to serve three major objectives: a) to raise awareness and to change risk-related behaviours; b) to enable dialogue and mutual understanding; and c) to improve relationships, cooperation and task coordination at the individual, organisational and/or community level. In the following, we discuss their potential contribution to the four kinds of social capacities.

\subsubsection{Communication to raise awareness and to change risk-related behaviours}

How to influence risk-related attitudes and behaviours through communication appears to be a main concern in the natural hazard-related literature. An integrated communication framework has been presented by O'Neill (2004) in the context of flooding at the community level (see Fig. 2).

O'Neill (2004) suggests that different communication tools are needed and the goals of communication vary according to the characteristics of the audience. Accordingly, people differ in their willingness to actively manage, rather than deny, risks and to adopt or change behaviours. The propensity to proactively engage with risks affects the time people need to adopt protective behaviours. O'Neill advises that the relatively small number of people in a

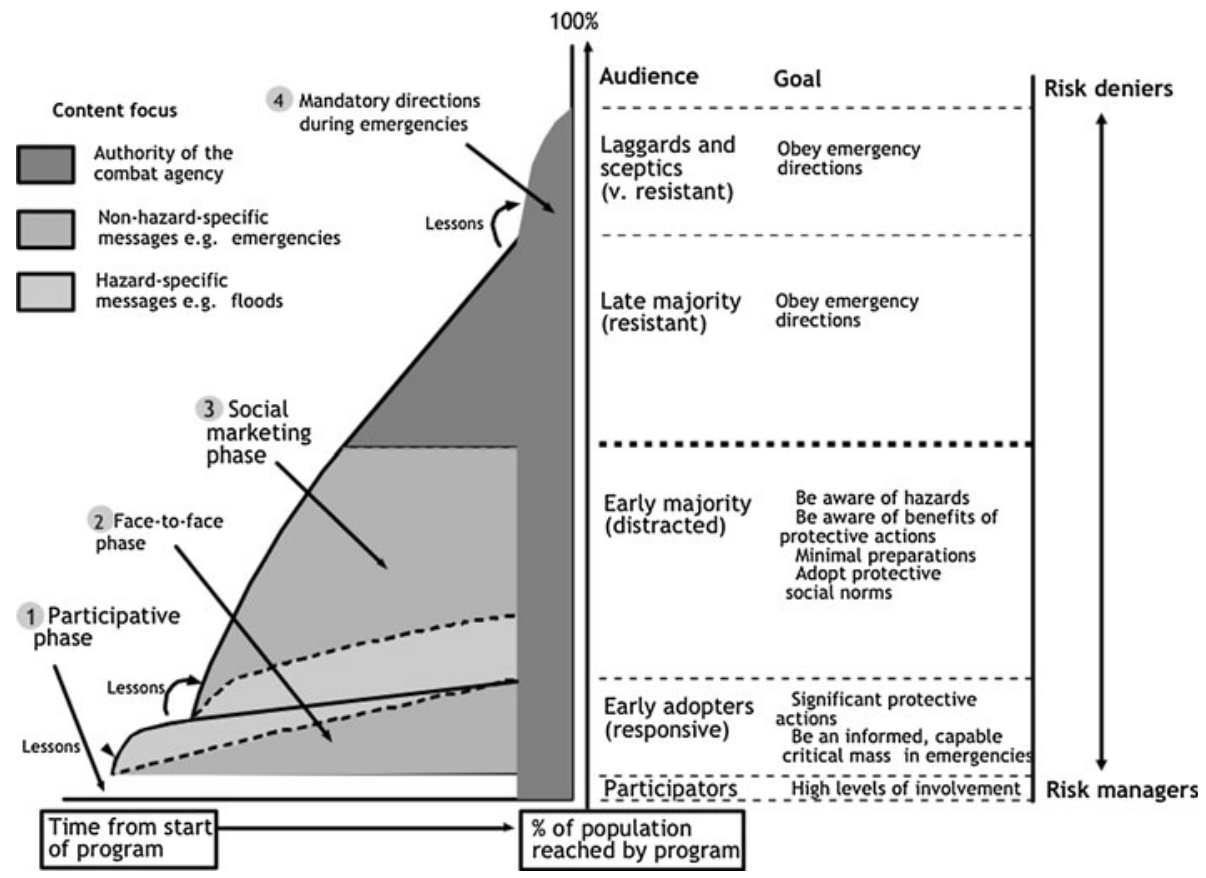

Fig. 2 Integrated model of risk communication (O’Neill 2004) 
community with a high willingness to invest time and energy in adopting actions should be involved from the very start of a communication programme and in a more participatory, faceto-face way to benefit from their local knowledge, creativity and time when developing community approaches. These very engaged individuals might act as 'local champions' or 'peer educators' to fellow residents. To encourage protective behaviour amongst those in denial about natural hazard risks or those resistant to change their behaviours, other communication tools, particularly social marketing techniques or campaigns, are more appropriate to get the message across about how to behave in particular situations. Although O'Neill developed the model for Australian communities, there is no reason why this could not be transferred to a European context. For example, Deeming (2008) discusses the role played by such local champions in localities threatened by storm surge flooding in the United Kingdom.

The model borrows from a number of the general conceptual approaches to risk communication, particularly the mental model approach with its focus on perceptions/characteristics of audiences and resulting communication needs, and the social network contagion approach (see Lundgren and McMakin 2009). For a small group of individuals, their involvement in a participatory process and face-to-face interaction might lead to the building of a number of capacities at the individual and community level. However, as summarised in Table 2, for most people targeted by one-way social marketing techniques, the potential for social capacity building appears to be more limited.

Table 2 Social capacity building communication models to raise awareness and to change risk-related behaviours

\begin{tabular}{|c|c|c|}
\hline & Individual level & Community level \\
\hline \multirow[t]{4}{*}{$\begin{array}{l}\text { Two-way } \\
\text { communication }\end{array}$} & $\begin{array}{l}\text { Knowledge capacities: build individual } \\
\text { knowledge on risks and ways to act and } \\
\text { the ability to find and understand } \\
\text { information }\end{array}$ & \\
\hline & $\begin{array}{l}\text { Attitudinal/motivational capacities: } \\
\text { develop self-confidence in knowledge } \\
\text { and personal abilities to critically } \\
\text { analyse information and to creatively } \\
\text { engage in finding solutions to a } \\
\text { problem; build a personal sense of } \\
\text { responsibility }\end{array}$ & \\
\hline & $\begin{array}{l}\text { Social/organisational capacities: develop } \\
\text { communication, organisation and } \\
\text { leadership skills; planning and outreach } \\
\text { skills }\end{array}$ & $\begin{array}{l}\text { Social/organisational capacities: } \\
\text { develop local ownership of the } \\
\text { communication programme; build } \\
\text { networks between individuals, } \\
\text { groups and organisations community }\end{array}$ \\
\hline & $\begin{array}{l}\text { Emotional/mental: develop capacities } \\
\text { and resources needed to better cope } \\
\text { with the psychologically adverse } \\
\text { effects of hazard events }\end{array}$ & \\
\hline \multirow{3}{*}{$\begin{array}{l}\text { One-way } \\
\text { communication } \\
\text { (e.g. social } \\
\text { marketing and } \\
\text { campaigns) }\end{array}$} & $\begin{array}{l}\text { Knowledge capacities: building up } \\
\text { knowledge on ways to act; ability to } \\
\text { find and understand information }\end{array}$ & \\
\hline & $\begin{array}{l}\text { Attitudinal/motivational capacities: } \\
\text { raised awareness; interest and } \\
\text { motivation to act; build a personal } \\
\text { sense of responsibility }\end{array}$ & \\
\hline & $\begin{array}{l}\text { Emotional/mental capacities: resources } \\
\text { needed to cope with anxiety and stress }\end{array}$ & \\
\hline
\end{tabular}




\subsubsection{Communication to enable dialogue and mutual understanding}

Other authors have worked on improving communication to elicit mental models and to enable mutual understanding. Translated back to the field of natural hazards, such communication may ultimately serve different ends, for instance socially robust decision-making, participatory problem framing, option appraisal and scoping or consensus building.

Kolkman et al. $(2005 ; 2007)$ for instance advocate a frame reflection and mental model mapping technique to enable mutual understanding between decision-makers, experts and stakeholders (in this case, representatives of special interest groups) in the context of integrated environmental assessment (EIA) and flood defence planning. In this way, the facilitated mutual learning process about alternative risk frames, the perspectives on possible responses and underlying assumptions, preferences and interests should ultimately help decision-makers to identify and address controversies at early stages of the planning process.

Similarly, Burgess and colleagues (2007) propose a deliberative mapping methodology to engage experts and citizens in an interactive dialogue on problem framing and option definition that might be adopted for the appraisal of natural hazard risks. Kenyon (2007) and Scolobig et al. (2008) have also recently presented participant-led multi-criteria approaches for evaluating flood mitigation measures in Scotland and Italy, respectively, whilst Stanghellini and Collentine (2008) have put forward a model for facilitating stakeholder participation in the management of catchment areas (CATCH model). Again, the focus is on structuring dialogue and deliberation amongst managers and stakeholders to ultimately enable mutual understanding and to resolve areas of conflict.

These communication models draw strongly on the social convergence communication approach (Rogers and Kincaid 1981) that conceptualises communication as a long-term process, which is shaped by the values of all actors involved. Furthermore, these models are clearly influenced by the social constructionist approach that challenges the notion that 'expert' understandings of risk are rational, whereas lay perceptions and behaviours are emotional and hence irrational (see Lundgren and McMakin 2009). Rather, all actors provide valuable knowledge and act according to alternative rationalities. Mostly, they focus on dialogical two-way communication between experts, decision-makers and key stakeholders, whilst the deliberate mapping approach makes explicit efforts to also involve citizens or the wider public in interactive communication processes. Such communication can contribute to different capacities at the individual and community level as shown in Table 3.

Table 3 Social capacity building in communication models that aim at enabling mutual dialogue and understanding

\begin{tabular}{lll}
\hline & Individual level & Community level \\
\hline $\begin{array}{l}\text { Two-way } \\
\text { communication }\end{array}$ & $\begin{array}{l}\text { Knowledge capacities: learning about other } \\
\text { actors with a stake in the handling of } \\
\text { risks, what they know, what they think } \\
\text { and why; knowledge on risks, hazards and } \\
\text { prevention measures }\end{array}$ & \\
& $\begin{array}{l}\text { Social/organisational capacities: } \\
\text { communication skills; ability to reflect } \\
\text { critically and to 'deal' with different } \\
\text { frames and perspectives; learning to } \\
\text { locate areas of agreement and } \\
\text { disagreement }\end{array}$ & $\begin{array}{c}\text { Social/organisational capacities: finding } \\
\text { and pursuing shared/collective goals; } \\
\text { forming communities of interest and/or } \\
\text { identity }\end{array}$ \\
\end{tabular}


Table 4 Social capacity building in communication models that aim at improving relationships and coordination

\begin{tabular}{lll}
\hline & Individual level & Organisation level \\
\hline $\begin{array}{l}\text { One-way and } \\
\text { two-way } \\
\text { communication }\end{array}$ & $\begin{array}{c}\text { Knowledge: learn where to get data, how } \\
\text { to use it and whom to contact } \\
\text { Social/organisational: communication } \\
\text { and organisation skills, improved } \\
\text { relationships (establishing and } \\
\text { stabilising relationships based on trust } \\
\text { and experience) }\end{array}$ & $\begin{array}{l}\text { Knowledge: learn to work together to } \\
\text { achieve shared goals } \\
\text { Social/organisational capacities: ability to } \\
\text { manage/share information and to } \\
\text { coordinate tasks, establishing and } \\
\text { multiplying formal and informal } \\
\text { communication channels within and } \\
\text { between organisations }\end{array}$ \\
\hline
\end{tabular}

\subsubsection{Communication to improve relationships, cooperation and coordination}

Another interesting way to approach risk communication on natural hazards has been put forward by McCarthy (2007). Drawing on intra- and inter-organisational communication approaches, he shows that communication on risks between and across the spectrum of riskmanaging entities before, during and after flooding events is as much about defining and improving relationships as it is about conveying information and direction. Accordingly, the management of natural hazards by public and private organisations can be understood as merging classical task-oriented approaches to communication with approaches that focus on strengthening relationships and human resources within and between organisations. These relationships and resources build the foundations for effective cooperation between departments, agencies and organisations with high task interdependencies (Bouwen and Taillieu 2004). To this end, organisations involved in the management of natural hazards need to apply a range of communication modes, channels and tools.

This approach probably has the most obvious links to social capacity building. Building up human resources and relationships within and between organisations is central to this approach. Developing these resources and relationships is therefore vital to better and more efficiently use information/knowledge and to coordinate/structure actions. Social capacity building potentially occurs at the individual and organisational level as summarised in Table 4.

The foregoing review indicates how different forms of communication could contribute to social capacity building within a society. Whilst approaches to build knowledge, attitudinal/motivational and social/organisational capacities appear to be well represented in the literature, there is little work on communication as a way to prepare people for the emotional and mental impacts of natural hazard events. Furthermore, our review shows that social capacity building has to be integrated into risk governance at various levels allowing for exchange between all involved authorities and experts and supporting both one- and two-way communication. In the following, we explore whether this is mirrored in risk communication practices in Europe.

\section{A review of risk communication practices in Europe}

The goal of this review was to map the range of current risk practices, rather than to present an exhaustive collection of existing communication projects. In this way, we were able to explore whether theoretical approaches to the communication of natural hazard risks are translated into practice and whether the range of practices is suitable for building different 
forms of social capacities. Consequently, we took an opportunistic approach to data collection using the wider network of the CapHaz-Net consortium as a starting point for the research. Specifically, consortium members and interested stakeholders whom we had contacted through workshops held in the early months of the project were asked to contact professionals working in the field of natural hazards risk communication (national authorities, practitioners and academics) with, ideally, a good overview of such communication practices in their respective countries. These professionals were then asked to point us towards innovative examples of such one- and two-way communication taking place within their countries. As this was an initial study-and following the approach taken in this paper-we decided to focus on communication between decision-makers, stakeholders and the public during the preparation and prevention phases of hazard management (as opposed to during the emergency or in the recovery phase).

Information on the practices-including their possible contribution to social capacity building-was gathered from 36 experts, most of them local and regional risk managers and scientists that were involved in the communication projects. To gather material in a standardised and comparable form, we used the guideline questions listed below.

- What types of hazards and risks are involved?

- What are the objectives of communication?

- What is being communicated?

- Who communicates with who?

- What channels and tools are being used?

- What are the good and/or poor qualities and the challenges?

- What is the contribution to social capacity building?

Most experts filled in the question form themselves $(n=22)$, whereas others preferred to be interviewed via phone $(n=9)$ or face-to-face $(=5)$. If available, we also reviewed promotional materials and project documents to complement the data. A short case study was then prepared for each practice, with Box 1 providing an example of one of these.

To evaluate the practices for their good and/or poor qualities, we compiled a checklist of good practice criteria from the wider risk communication literature (Lundgren and McMakin 2009; Mileti et al. 2004; Renn 2008). We considered general principles and principles specifically applying for one-way and two-way communication (see Table 5).

In total, 60 cases were inventoried in 16 countries. The case description and evaluation of websites and online communication platforms were based mainly on the assessment of the authors. Findings for other practices were based on expert views and project documentations. Using the guiding questions and the checklist introduced above, we ensured largest possible consistency across the 60 practices.

A full description of these 60 practices can be found at Appendix in Electronic supplementary material. Here, we concentrate on the key results and characteristics that emerged when we analysed the practices in relation to the insights gained from the literature presented here.

\section{Risk communication and social capacities: good practice and challenges}

To provide an overview of the practices, Table 6 catalogues them in terms of the types of hazards they deal with, the spatial scale at which they operate and the main purpose of the 
Box 1 Example description of a one-way communication practice (all descriptions are available from Appendix in Electronic supplementary material

\begin{abstract}
Practice \#60 'Making people flood wise' flood awareness raising campaign, Environment Agency, UK; continuous since 1998

Type of hazards and the risks involved: Fluvial and coastal flooding

Objectives: To raise awareness, to inform to encourage people to prepare in advance of flooding and to take appropriate action in response to flooding, and to build trust within communities.

Who communicates? Environment Agency, local champions and local partnership organisations to the public at-risk (people living, working and travelling in flood risk areas).

Communication tools/channels: Mainly through one-way communication tools and through diverse channels, e.g. advertising in local TV, radio, press, floodline pack and directories, flood guides, flood product booklets, business online flood guide, flood warning services and public events such as Gardeners World and a Flood Awareness Week.

Good or/and poor qualities: The practice stands out as a multi-step and long-term communication strategy that is well planned from the outset and that changes its focus and its contents according to the needs of the audience, i.e. year 1: raising awareness, year 2: transfer of awareness into action, years 3-5: maintain awareness and encourage action, year 5: information and support to take action, years 6-7: maintain awareness and focus on specific groups, years 8-9: maintaining awareness, information and support at the local level, year 10: community engagement and trust building, year 11 and onwards: local and targeted activities. The needs of the audience were investigated and the results were used to develop the communication programme. Celebrity endorsement helps to gain people's attention. A diversity of communication tools and channels are used and the target levels of the communication programme are clear, and are being evaluated across all eight targeted regions. Indirect and face-to-face communication are coupled as the latter seems to be most effective in encouraging people to take preparatory actions.

Contribution to social capacity building: The practice aims at raising risk awareness of at least $55 \%$ of the audience. Of those who are aware of the risks, $63 \%$ should take preparatory actions in advance of flooding. $10 \%$ of 'vulnerable' people should be informed of their flood risk.
\end{abstract}

communication. These categories are not mutually exclusive, so that a practice could be counted in more than one category if needed.

As Table 6 shows, the reviewed practices are dominated by flood-related communications. This is mainly due to the fact that flood events occur in most European countries, whereas avalanches, storm surges or earthquakes are much more dependent on specific locations and topographies and are thus less ubiquitous. We can also see a dominance of one-way communication practices that seek to provide information, raise awareness and warn of events. When we analysed the reviewed practices in more detail, we found that this one-way transfer mainly takes the form of information campaigns as well as forecasting and warning systems and is disseminated through approaches ranging from one (e.g. brochures) to several channels (e.g. website, mobile phone, television and radio).

Scale was also important here as two-way communication between authorities, stakeholders and the public at risk appears limited largely to the local level of the municipality and is applied mainly to floods and less to other natural hazards. These practices usually aim at facilitating social participation in the planning and/or implementation of structural and/or non-structural mitigation measures. A closer look at the rationale for participation reveals that, in most cases, such participation mainly serves to promote a wide acceptance of measures amongst residents rather than facilitating a more profound discussion on the benefits and the costs of mitigation measures, the residual and emerging risks, the thresholds of acceptable risks and of the desirable safety levels. Who gains and who loses from structural and non-structural prevention measures and how this relates to solidarity 
Table 5 Checklist of good risk communication

\begin{tabular}{|c|c|c|}
\hline $\begin{array}{l}\text { General criteria of good risk } \\
\text { communication (Lundgren and } \\
\text { McMakin 2009; Mileti et al. 2004; } \\
\text { Renn 2008) }\end{array}$ & $\begin{array}{l}\text { Criteria of good one-way } \\
\text { communication (Mileti et al. 2004, } \\
\text { CapHaz-Net expert workshop in } \\
\text { Ljubljana in June 2010) }\end{array}$ & $\begin{array}{l}\text { Criteria of good two-way } \\
\text { communication (Lundgren and } \\
\text { McMakin 2009, Renn 2008) }\end{array}$ \\
\hline
\end{tabular}

A communication scheme, strategy or programme are in place

The purposes and objectives of communication efforts are clear

The roles, responsibilities and resources of the involved actors are clear

It is clear who the 'audience' is

Communicators have analysed the key characteristics, perceptions, concerns and knowledge of the audience

The communication modes, channels and tools match with the purposes, the situation and the needs of the audience

The communication process and the outcomes are evaluated
Communication is repeated and ongoing rather than one-off

Clear, simple language is used rather than purely technical or statistical terms and probabilities

The information is consistent and supports people in their search for more information

Communication gives clear advice on how to behave

A mix of verbal, written and visual communication to gain people's attention without appearing superficial or simplistic

Additional information should be placed in the community and local people help to disseminate and champion information

Information is accessible for special groups and is provided in multiple languages

Communicators work proactively with the media

Uncertainty is communicated openly

Communicators use 'windows of opportunity' after a hazard event that might increase the general openness for information

Adequate resources to design and conduct communication professionally should be allocated
There are adequate financial resources and time for the process

A written interaction/ participation plan exists

Involvement should start early and run throughout the risk management process

Organising bodies should be committed to listening to, and acting on the issues raised

Organising bodies should actively communicate how the stakeholders' or the public's contributions influence their work and decisions

Relevant stakeholders should be carefully identified and equally represented in the process

All relevant information and decisions should be openly communicated and made available to the participants

All stakeholders should have equal access and capacity to participate

Dialogic communication tools should be led by a neutral and professional moderator or mediator

within and between municipalities are questions that are rarely addressed in these communication practices. Here, we can also see the importance of wider governance processes (Walker et al. 2010a) as well as the economic context as, particularly in Eastern and Southeastern Europe, there were hardly any examples of successful two-way communication due to the dominance of top-down planning regimes (Komac 2010 in Höppner et al. 2010) and a lack of funding (Maghiar, Stanciugelu and Armas 2010 in Höppner et al. 2010).

The practices were further reviewed for good qualities using the information provided by project experts. Table 7 summarises the findings from all 60 practices. These qualities are robust in that they would support effective communication in any geographic context. They relate mainly to the project frame, the content and design of communication, the language and tools being used, the timing of communication and the availability of information, and outreach activities. For instance, a written communication plan and a mix 
Table 6 Summary of communication practices

\begin{tabular}{|c|c|}
\hline Hazards & $\begin{array}{l}\text { Floods }(40) \text {, debris flows }(8) \text {, landslides }(7) \text {, storms }(6) \text {, heatwaves }(5) \text {, snow } \\
\text { avalanches }(4) \text {, storm surges }(4) \text {, rockfall (3), droughts }(3) \text {, earthquakes ( } 3) \text {, } \\
\text { rock avalanches (2), forest fires (2) }\end{array}$ \\
\hline Spatial scale & $\begin{array}{l}\text { Local (24), national (13), national-regional (8), regional-local (6), national- } \\
\text { regional-local (4), regional (3) }\end{array}$ \\
\hline $\begin{array}{l}\text { Communication mainly } \\
\text { serves to }\end{array}$ & $\begin{array}{l}\text { Provide information and raise awareness (46), warn of events }(22) \text {, train for } \\
\text { emergencies (12), forecast events (11), implement non-structural measures } \\
\text { (10) [land-use planning (6), risk/hazard maps (4)], plan non-structural } \\
\text { measures (8) [land-use planning (7), risk/hazard map (1)], plan structural } \\
\text { measures (7), implement structural measures (7) }\end{array}$ \\
\hline
\end{tabular}

For the purposes of this paper, structural methods are considered to involve the introduction of physical structures, such as debris catchers or flood defence walls, whilst non-structural methods refer to other kinds of solutions, such as the creation of hazard maps or attempts to reduce the risks from hazards through careful land-use planning

of different tools and channels that fit the audience needs were considered strengths of some of the reviewed practices. A number of flood-prone cities effectively combine maps, public events, visual presentations and art and media reports to raise awareness, whilst permanent tools such as flood markers help to keep the memory of past events alive. Furthermore, wide availability of up-to-date information as well as clear and intuitive design was highlighted as good practice by the stakeholders on whose views the practice reviews were based.

However, we also noted considerable challenges that are summarised in Table 7. For instance, the fragmentation of responsibilities and competencies, as well as administrative divisions, was reported by the stakeholders as a serious obstacle to an effective chain of information and warning delivery. Inconsistencies between campaigns and their core messages were also highlighted as challenges, particularly at the national level. For example, the 'Go in, Stay in, Tune in' advice issued by the 'Preparing for Emergencies' campaign in the United Kingdom (practice \#51, Appendix in Electronic supplementary material) contradicts a campaign run by the UK Fire and Rescue Services, whose common sense catch phrase is 'Get Out, Stay Out, Call Us Out'. Similarly, multiple sources of warning and information messages may lead to confusion and ultimately reduce the credibility of both the information and the sender.

Two-way communication practices also have their challenges, with key problems mentioned by stakeholders including existing local socio-political conflicts, a limited amount of room to actually influence planning decisions and, at times, a reluctance to even conduct such time-consuming processes on the part of both authorities and the local public.

Another point of criticism is that, whilst the reviewed practices offer a range of promising tools to communicate on natural hazards, they are rarely embedded in a more comprehensive and long-term strategy. For instance, risk maps or forecasting systems were not necessarily well advertised amongst the public through additional information materials or events.

Of particular relevance to social capacity building is the fact that the bulk of communication practices was aimed at developing knowledge capacities $(n=49)$ and attitudinal/ motivational capacities $(n=45)$ rather than fostering social/organisational $(n=23)$ and emotional/mental capacities $(n=2)$. With respect to attitudinal/motivational capacities, the building of risk awareness dominates whilst considerably fewer practices attempt to 
Table 7 Good aspects, poor practice and challenges of the reviewed practices

Good practice $\quad$ Poor practice and challenges

\section{Project frame}

A communication plan exists that outlines the purposes and the timing of communication efforts as well as the channels and tools to be used

Responsibilities are clearly assigned, and it is clear who the audience is

There is a regular evaluation that serves as the basis for improvements

Communication is a long-term effort rather than a one-off event

\section{Content}

Matches the needs of the audience and is tailored to vulnerable groups

Information is clear, concise and complete

Content is informative yet entertaining and curiosity arousing

Gives information to help people assess their own vulnerability and provides specific behaviour advice and instruction to reduce it

Communicates self-responsibility rather than giving a false sense of security

Explicitly addresses the adverse psychological impacts of hazard events

Supports people in their search for more information or help

Language

Language is clear and simple without being patronising or simplistic

Does not rely on purely technical or statistical terms and probabilities

\section{Outreach/availability}

Communication channels and tools are widely available

Local networks and peer-to-peer communication are used to spread information

Proactive work with the media

\section{Communication tools and channels}

Different communication channels and tools are used and fit the purposes of communication.

Easy to use (e.g. user-friendly navigation in online flood forecasting systems) and allow quick finding of information

\section{Design}

The design is graphically concise, intuitive (e.g. colours on maps) and allows a quick and broad understanding of information

The design of icons is harmonised to increase readability across Europe (e.g. severe weather warning systems)
Project frame

Fragmentation of communicators and unclear division of responsibilities

Complacency with achievements and one-off efforts only

Lack of willingness to communicate on behalf of both risk-managing bodies and the public

Unfavourable conditions for participatory processes in particular (e.g. lack of/unprofessional moderation, no room for negotiation, biased selection of participants)

\section{Content}

Inconsistencies between messages (e.g. contradictory behaviour advice in different information campaigns)

Incorrect messages (e.g. false warnings) might undermine their credibility and trust in services

Information is often too generic and not targeting specific groups

\section{Language}

Expert-dependent terms (e.g. 100-year flood) and probabilities are perceived very differently across individuals

Lack of scientific advice on how to frame risk messages in particular situations

Outreach/availability

Communication channels (e.g. internet) are not available to all

High media attention may trigger 'event tourism'

\section{Awareness}

Frequent communication (e.g. warnings) may reduce vigilance

General awareness of communication tools is low (e.g. risk maps)

\section{Trust and conflicts}

Lack of trust in communicating bodies

Variety of interests and existing socio-political conflicts, for example, perceptions of inequity and unfairness of mitigation measures and a lack of solidarity in communities can compromise the acceptance of management measures 
Table 7 continued

\begin{tabular}{ll}
\hline Good practice & Poor practice and challenges \\
\hline Timing & Resources \\
The information is up-to-date and continuous & High costs, time- and energy-consuming \\
The content and intensity of communication follow & Lack of funding \\
the temporal development of hazards (particularly & \\
in the case of seasonal hazards like droughts) & \\
A combination of one-off, episodic and permanent & \\
communication is used (e.g. exhibitions, & \\
newsletters and flood markers) to both arouse & \\
interest and keep memory alive &
\end{tabular}

strengthen people's sense of self-efficacy and agency. Interestingly, only 20 out of 60 cases have been empirically evaluated with respect to their actual effects.

We furthermore found that only a few communication efforts $(n=6)$ actually corresponded with the three theoretical approaches to risk communication that we outlined in Sect. 3.2. The United Kingdom 'Making people floodwise' campaign (see Box 1) is one of the rare examples of a comprehensive and long-term strategy to raise and sustain the awareness of flood-affected communities over the years. Funded by the Environment Agency as part of the UK Flood Warning Investment Strategy, this practice stands out as a multi-step strategy that was well planned from the outset and that alters its focus and contents according to local needs that are continuously investigated (e.g. raising and sustaining awareness, transferring awareness into action, building trust and community engagement). A diversity of tools and channels are used such as booklets, festivals, media advertisement and flood warning services, and the campaign is being evaluated across all eight targeted regions. One-way information is coupled with face-to-face conversation with local residents as the latter seems to be most effective in encouraging people to take preparatory action and to spread messages in the communities.

A further good practice example of dialogue-oriented communication is the so-called Etsch-Dialogue in South Tyrol in Italy (practice \#21, Appendix in Electronic supplementary material). The Etsch-Dialogue is one of the projects through which the province of South Tyrol implements the EU Water Framework Directive and it is financially supported by the EU. Nearly 60 representatives from 45 organisations, interest groups and province authorities met regularly over 2 years to jointly deliberate on structural and non-structural flood and debris flow prevention measures. Additionally, the public in the six affected communities along the river Etsch was kept informed through diverse information materials that were professionally designed by a public relations agency as well as through the media, excursions and exhibitions. Although not empirically evaluated, the regular stakeholder dialogues have arguably facilitated exchange and networking between participants. In fact, stakeholders have committed to meet in the future to continue to cooperate and establish working groups.

Finally, flood partnerships in Germany represent good examples of communication that aims at improving the cooperation between all risk-managing authorities of a catchment area and the coordination of their prevention and emergency actions (practice \#15, Appendix in Electronic supplementary material). Regular meetings help authorities to coelaborate risk maps, public information material, forecasting and warning systems as well as land-use plans that go beyond single municipalities. Of particular note is that these three examples not only target knowledge and attitudinal capacities (e.g. awareness and self- 
efficacy) but also social and organisational capacities (e.g. communication and organisation skills, trustful relationships and ability to share tasks).

The 'Making people floodwise' campaign, the Etsch-dialogue and the flood partnerships are examples for long-term comprehensive communication strategies with different objectives. These practices follow a multiple-tool approach that is tailored to the specific situation and audience and sensitive to changing communication needs. Lessons from such practices can serve as a valuable basis for improving future communication efforts across Europe.

\section{Recommendations for communication practice}

Our exploratory review of risk communication practices and the empirical examples suggest that few communication efforts actually correspond with models propagated in the natural hazards literature, thereby building different types of social capacities in concert. However, the bulk of the reviewed practices include good or innovative elements that could be combined to produce more integrative and effective communication strategies. Indeed, whilst many promising tools are currently being trialled, they are often disparate and not embedded in more comprehensive long-term communication strategies.

Based on lessons from the inventory and the literature, Table 8 describes what such communication strategies amongst authorities, stakeholders and the public might look like in the prevention, preparation and warning phases for natural hazards. It also indicates further good practice examples from the inventory (available from Appendix in Electronic supplementary material).

First of all, a long-term strategy that pays attention to different communication needs seems necessary to prepare people for the adverse impacts of natural hazard events and to prepare the ground for more effective warning and emergency services. Such a strategy not only aims at raising awareness but also at sustaining it over the years and specifically targets knowledge and motivational as well as emotional capacities. At the same time, twoway communication in appraisal and decision-making processes potentially strengthens social and organisational capacities and supports shared solutions (e.g. planning decisions, local communication and warning tools).

Whilst these strategies should be applicable across the spectrum of natural hazards, we stress, as others before (e.g. Sorensen 2000), that there is no single best guide for all situations. Consequently, multiple-tool approaches appear to offer an effective way of building long-term communication strategies in ways that may also enhance social capacities. Such approaches enable communications to be tailored to reinforce each other whilst also accommodating the specific context of the hazard situation and changing communication needs as a result of shifting positions within the hazard cycle (Fig. 1). Crucially, multiple-tool approaches also have sufficient versatility to accommodate the varied needs of community members and, of course, the wider risk governance context, including the need to build stronger relationships and dialogue within and between the public and the relevant local and national stakeholders. For example, whilst it represents a largely one-way form of communication, the Environment Agency's 'Making People Flood Wise' campaign (Practice \#60 - see Box 1) shows promising aspects in that it employs multiple forms of communication—some of which go beyond the emergency management sphere in a bid to make links with the wider community. For example, by attending events which are not focused on flooding, such as the Gardeners World Live show, the Environment Agency is attempting to build relationships with wider audiences 


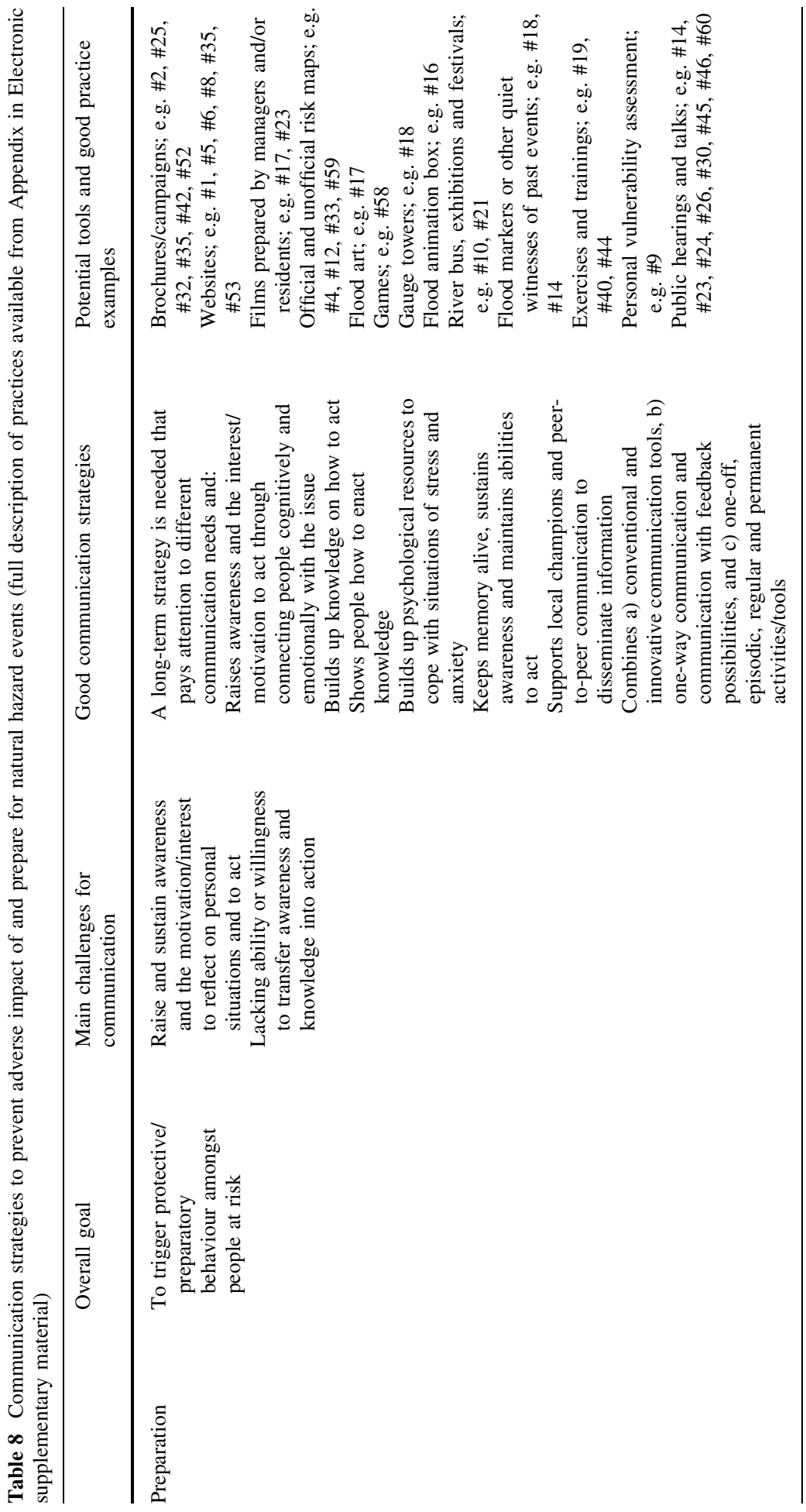




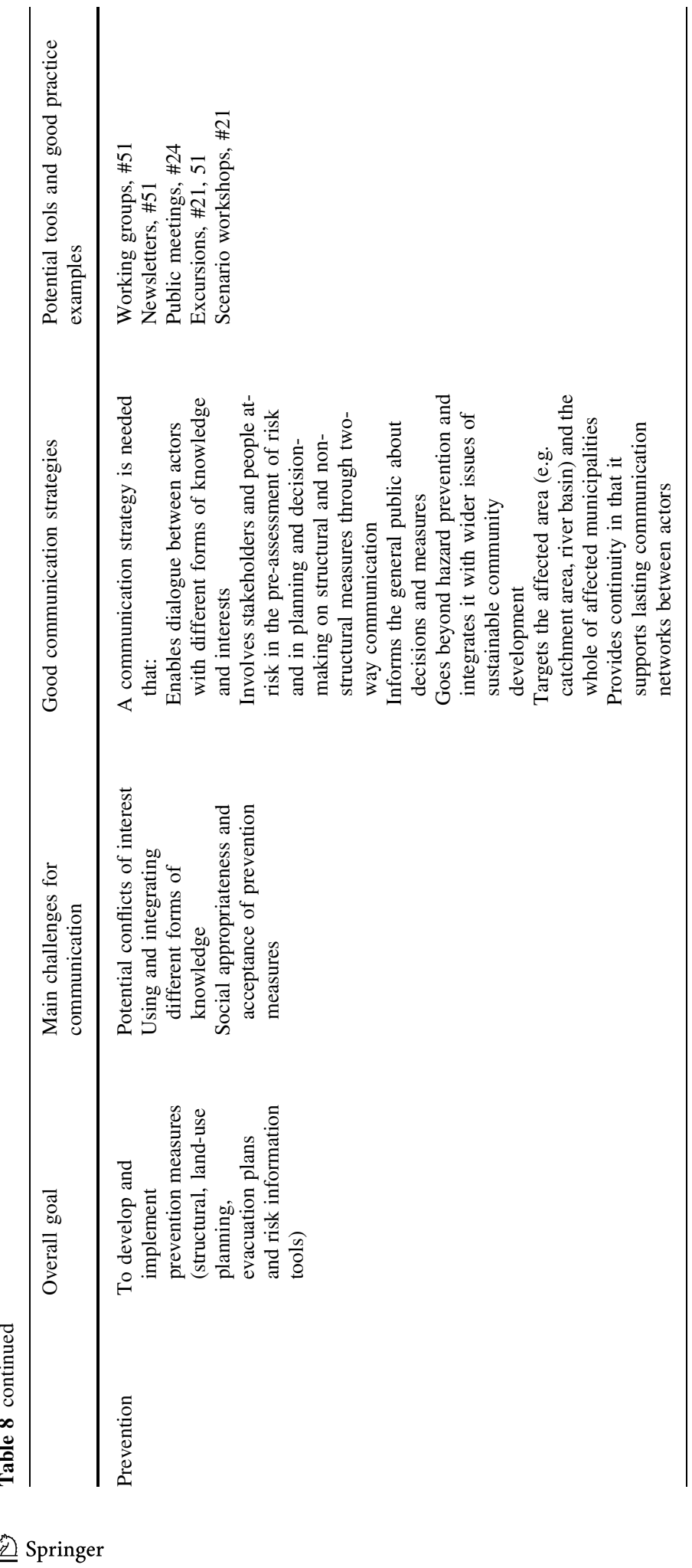




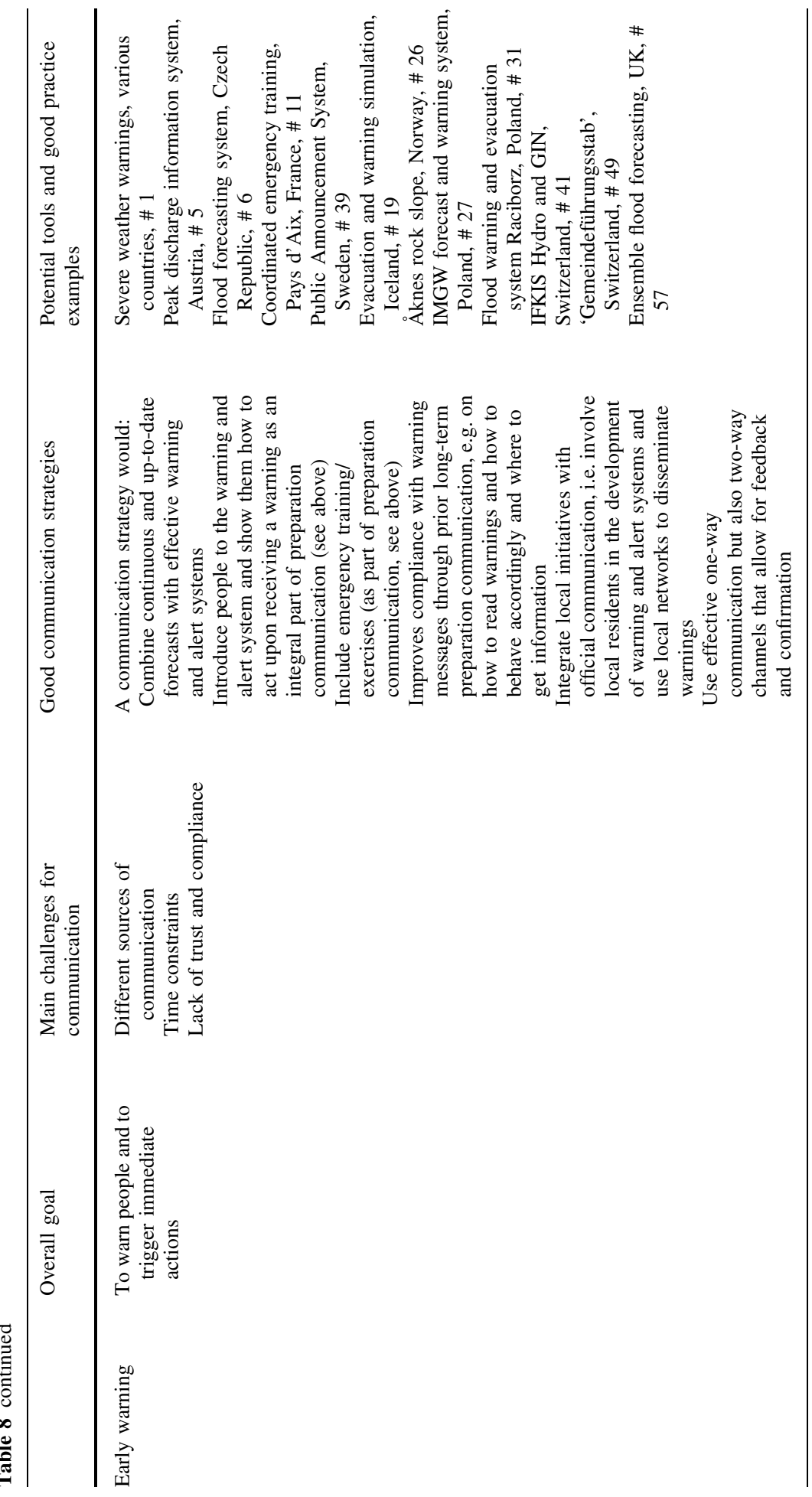


who may not normally engage with hazard planning. Of course, the use of a multiple-tool approach is also adaptable to different positions within the hazard cycle, with other, more immediate methods and techniques being able to build on the longer-term, more 'everyday' forms of communication, should a crisis occur. For example, in the event of a flood event, the Environment Agency can call on its Floodline Warnings Direct service, which can warn people of an event by telephone, text or email.

\section{Conclusions}

By reviewing the interrelationships between risk communication and social capacity building in theory and practice, this paper contributes to the field of natural hazards research by integrating two hitherto separate strands of the literature. Combining these literatures has allowed us to draw four key conclusions.

Firstly, we have introduced a typology of social capacities and have argued that, depending on the communication approach one takes, knowledge, attitudinal/motivational, social/organisational and emotional/mental capacities can be targeted to different extents. We have also shown that such a typology can serve as one basis for a systematic evaluation of risk communication practices.

Making such evaluations appears particularly important given that a second key finding of our review is the existence of a gap between the theory and practice of risk communication in a European context. Specifically, we identified a disconnect between the recommendations for long-term, coordinated communication strategies that can be found in the research literature (e.g. Hagemeier-Klose and Wagner 2009; O'Neill 2004) and the isolated nature of the many promising practices and tools that are currently being trialled in Europe. Based on our review of both literature and practice, we have recommended that if risk preparedness is to be improved, a longer-term, multiple-tool strategy is needed that builds up emotional and mental resources and knowledge on how to act, which keeps memory alive and combines episodic, regular and permanent tools. If promoting risk prevention measures is the main goal, the diversity of interests shall be considered by enabling a lasting dialogue between stakeholders and by informing the wider public.

Thirdly, and following from this second conclusion, our research suggests that the ability to foster social capacities should be added to the list of factors to consider when designing risk communication initiatives. Currently, the literature recommends that the mode and format of the communication should be tailored to the characteristics, complexity and ambiguity of the risks at hand (Renn 2005, 2008). However, our review of the relevant literatures shows that it could also be beneficial to include social/organisational and emotional/mental capacities as they are valuable basic resources that may help people, communities and organisations to better deal with a range of external stressors and hazards.

Building in a role for social capacities is particularly important because our review of risk communication practices across Europe indicates that few of these practices aim to build people's sense of agency and efficacy or consider the social/organisational capacities that may improve cooperation and coordination between people and institutions and, in so doing, potentially create wider social benefits for the community that go beyond keeping people safe from hazards. Instead, the majority of current communication practices that we reviewed are one-way efforts that are focused solely on improving hazard knowledge or raising risk awareness. Whilst practices which aim exclusively to increase knowledge capacities and risk awareness are well intentioned, they also are problematic, because they rest on an overly simplistic model of human behaviour (the assumption that people act as rational individuals 
whose behaviour will change if only they are provided with more/better information on a subject). They thus suggest adherence to an outmoded 'deficit' model of one-way communication (Hilgartner 1990; Frewer 2004). Indeed, our review indicates that it remains a challenge to trial two-way, participatory communication projects that involve those people at risk, particularly in the pre-assessment and appraisal phase of risk situations, but also in the planning of prevention measures. This is already happening in other risk-related fields (e.g. Horlick-Jones et al. 2007) and we have highlighted promising models and practices such as mental mapping, deliberative mapping or different forms of stakeholder dialogue for the context of natural hazards (e.g. Kolkman et al. 2005; Kenyon 2007; Scolobig et al. 2008; Burgess et al. 2007). However, such ways of working have not been trialled extensively in the natural hazards field.

Fourthly, the data generated for our preliminary study suggest that remarkably few communication practices have actually been evaluated. As a result, there is little reflection on how the framing, timing and design of communication initiatives may influence their effectiveness. This lack of more systematic evaluation is not a purely European phenomenon but has been reported elsewhere (e.g. Rohrmann 1998). Therefore, it remains a challenge to find ways to better institutionalise evaluations into risk management practice. For instance, it might be possible to incorporate such evaluations into existing vulnerability or resilience assessments. Whilst structured surveys may serve to find out whether messages have actually reached their target group, interviews, group discussions and stakeholder workshops can be used to test whether the design, language, content and timing of risk communication meet the needs of the target groups. Repeated surveys are a way to measure social capacities and risk-related behaviours before and after communication initiatives to asses the actual effectiveness of risk communication.

Finally, we hope that this exploratory review stimulates further efforts to survey-and learn from-risk communication practice. In particular, we believe that it is important to explore the possible relationships between communication and social capacity during the longer-term recovery period that follows a disaster. An exploration of communication between residents and the various public and private (e.g. insurers and builders) stakeholders involved in the recovery process - and the effects of this on social capacitiescould prove very valuable.

Acknowledgments This research was financially supported by the European Union (European Commission, FP7 Contract No. 227073). This review has benefited from the expertise of many colleagues and communication practitioners in a number of European countries. In particular, we would like to thank Andreas Pichler, Teun Terpsta, Irina Stanciugelu, Alin Maghiar, Iuliana Armas, Nigel Watson, Edda Bergner, Gisela Wachinger, Simon McCarthy, Fiona Tweed, Blaž Komac, Christian Willi, Jelena Ćalić, Marko V. Milošević, Wojciech Biernaki, Jarek Dzialek, Gordon Walker, Chiara Bianchizza, Bruna De Marchi, Luigi Pellizzoni, Anna Scolobig, Annett Steinführer, Daniela Siedschlag, Christian Kuhlicke and Meera Supramaniam. Thanks go to Borries Schwesinger for graphic support. Michael Bründl thanks the Center for Interdisciplinary Research $(\mathrm{ZiF})$ for the excellent support during his stay as fellow in the research group 'Communicating Disaster' at $\mathrm{ZiF}$.

Open Access This article is distributed under the terms of the Creative Commons Attribution License which permits any use, distribution, and reproduction in any medium, provided the original author(s) and the source are credited.

\section{References}

Adger WN, Hughes TP, Folke C, Carpenter SR, Rockström J (2005) Social-ecological resilience to coastal disasters. Science 309(5737):1036-1039 
Anderson M, Woodrow P (1989) Rising from the Ashes. Intermediate Technology Publications, London, Development Strategies in Times of Disasters

Bandura A (1986) Social foundations of thought and action: a social cognitive theory. Prentice-Hall, Englewood Cliffs

Beierle TC, Konisky DM (2000) Values, conflicts, and trust in participatory environmental planning. J Policy Anal Manag 19(4):587-602

Berkman LF, Glass TA (2000) Social integration, social networks, social support, and health. In: Berkman LF, Kawachi I (eds) Social epidemiology. Oxford University Press, New York

Bier VM (2001) On the state of the art: risk communication to the public. Reliab Eng Syst Saf 71:139-150

Bollin C, Hidajat R (2006) Community-based disaster risk index: pilot implementation in Indonesia. In: Birkmann J (ed) Measuring vulnerability to natural hazards: towards disaster resilient societies. United Nations University Press, New York, pp 271-289

Bouwen R, Taillieu T (2004) Multi-party collaboration as social learning for interdependence: developing relational knowing for sustainable natural resource management. J Community Appl Soc Psychol $14: 137-153$

Buchecker M (2008) Welche Ansprüche hat die Bevölkerung an ihre Wohnumgebung? Forum für Wissen:43-54

Buchecker M, Meier C, Hunziker M (2010) Measuring the effects of consensus-building processes with methods of intervention research. Eur Plan Stud 18(2):259-280

Burgess J, Stirling A, Clark J, Davies G, Eames M, Staley K, Williamson (2007) Deliberative mapping: a novel analytic-deliberative methodology to support contested science-policy decisions. Public Underst Sci 16:299-322

Conchie SM, Burns C (2008) Trust and risk communication in high-risk organizations: a test of principles from social risk research. Risk Anal 28(1):141-149

Cook A, Watson J, Van Buynder P, Robertson A (2007) 10th anniversary review: natural disasters and their long-term impacts on the health of communities. J Environ Monit 10(2):167-175

Deeming H (2008) Increasing resilience to storm surge flooding: risks, social networks and local champions. In: Samuels P, Huntington S, Allsop W, Harrop J (eds) Flood risk management: research and practice. CRC Press, Taylor and Francis Group, pp 945-955

DeSalvo KB, Hyre AD, Ompad DC, Menke A, Tynes LL, Munter P (2007) Symptoms of posttraumatic stress disorder in a New Orleans workforce following Hurricane Katrina. J Urban Health 84(2):142-152

Ereaut G, Segnit N (2006) Warm words: how are we telling the climate story and can we tell it better?. Institute for Public Policy Research, London

Faulkner H, Ball D (2007) Environmental hazards and risk communication. Environ Hazards 7:71-78

Fernández-Bilbao A, Twigger-Ross C (2009) More targeted flood warnings: a review improving institutional and social responses to flooding. Science report SC060019 work package 1b. Environment Agency, Bristol

Fichter H, Jähnke P, Knorr-Siedow T (2004) Governance capacity für eine wissensbasierte Stadtentwicklung. In: Matthiesen U (ed) Stadtregion und Wissen. VS Verlag für Sozialwissenschaften, Wiesbaden, pp 309-336

Frewer L (2004) The public and effective risk communication. Toxicol Lett 149:291-397

Futerra (2010) Sizzle: the new climate message. Available from www.futerra.co.uk/downloads/ Sellthesizzle.pdf. Accessed 29 April 2010

Gupta J, Termeer C, Kostermann J, Meijerink S, van den Brink M, Jong P, Nooteboom S, Bergsma E (2010) The adaptive capacity wheel: a method to assess the inherent characteristics of institutions to enable the adaptive capacity of society. Environ Sci Policy 13:459-471

Hagemeier-Klose M, Wagner K (2009) Evaluation of flood hazard maps in print and web mapping services as information tools in flood risk communication. Nat Hazards Earth Syst Sci 9:563-574

Heath R, Palenchar M (2000) Community relations and risk communication: a longitudinal study of the impact of emergency response messages. J Public Relat Res 12(2):131-161

Hilgartner S (1990) The dominant view of polarization: conceptual problems, political uses. Soc Stud Sci 20:519-539

Höppner C, Frick J, Buchecker M, Elsasser H (2005) Evaluating a new participatory planning approach for sustainable landscape development in Switzerland-participatory techniques and social effects of landscape development concepts (LDC). In: Brebbia CA, Kungolos A, Beriatos E (eds) Sustainable development and planning II. Transactions of the Wessex Institute, vol 2. WITPress, Ashurst, pp 1329-1341

Höppner C, Frick J, Buchecker M (2007) Assessing psycho-social effects of participatory landscape planning. Landsc Urban Plan 83(2-3):196-207 
Höppner C, Buchecker M, Bründl M (2010) Risk communication and natural hazards. CapHaz-Net WP5 report

Horlick-Jones T, Walls J, Pidgeon N, Poortinga W, Murdock G, Riordan T (2007) The GM debate: risk, politics and public engagement. Routledge, London

Kashefi E, Walker G (2009) How the public and professional partners make sense of information about risk and uncertainty-literature review. Science Project SC070060. Environment Agency, Bristol

Kasperson RE, Golding D, Tuler S (1992) Social distrust as a factor in siting hazardous facilities and communicating risks. J Soc Issues 48(4):161-187

Kenyon W (2007) Evaluating flood risk management options in Scotland: a participant-led multi-criteria approach. Ecol Econ 64:70-81

Kolkman MJ, Kok M, Van der Veen A (2005) Mental model mapping as a new tool to analyse the use of information in decision-making in integrated water management. Phys Chem Earth 30:317-332

Kolkman MJ, Van der Veen A, Geurts P (2007) Controversies in water management; Frames and mental models. Environ Impact Assess Rev 27:685-706

Kuhlicke C, Steinführer A (2010) Social capacity building for natural hazards. A conceptual frame. CapHazNet WP1 Report. Helmholtz Centre for Environmental Research-UFZ, Leipzig

Kuhlicke C, Steinführer A, Begg C, Buchecker M, De Marchi B, Höppner C, Komac B, McCarthy S, Renn O, Tapsell S, Wachinger G, Walker G, Whittle R (2010) Knowledge inventory. State of the art of natural hazards research in the social sciences and further research needs for social capacity building. CapHaz-Net WP10 Report. Helmholtz Centre for Environmental Research-UFZ, Leipzig

Kuhlicke C, Steinführer A, Begg C, Bianchizza C, Bründl M, Buchecker M, De Marchi B, Di Masso Tarditti M, Höppner C, Komac B, Lemkow L, Luther J, McCarthy S, Pellizzoni L, Renn O, Scolobig A, Supramaniam M, Tapsell S, Wachinger G, Walker G, Whittle R, Zorn M, Faulkner H (2011) Perspectives on social capacity building for natural hazards: outlining an emerging field of research and practice in Europe. Environ Sci Policy 14(7):804-814

Lakoff G (2010) Why it matters how we frame the environment. Environ Commun J Nat Cult 4:70-81

Leach WD, Pelkey NW, Sabatier PA (2002) Stakeholder partnerships as collaborative policymaking: evaluation criteria applied to watershed management in California and Washington. J Policy Anal Manag 21(4):645-670

Lundgren RE, McMakin AH (2009) Risk communication: a handbook for communicating environmental, safety, and health risks. WILEY, New Jersey

Manojlovic N, Pasche E (2008) Integration of resilienc measures into flood risk management concepts of communities. Flood Recovery Innov Response WIT Trans Ecol Environ 118:235-245

McCarthy S (2007) Contextual influences on national level flood risk communication. Environ Hazards $7(2): 128-140$

Mileti DS (1999) Disaster by design: a reassessment of natural hazards in the United States. Joseph Henry Press, Washington

Mileti D, Nathe S, Gori P (2004) Public hazards communication and education: the state of the art. Available from http://userweb.port.ac.uk/ gilesd/Documents/Geohazards\%20WP/nhc_informer2update.pdf. Accessed 1 April 2011

Mort M, Convery I, Bailey C, Baxter J (2004) The health and social consequences of the 2001 foot and mouth disease epidemic in North Cumbria Available from: www.lancs.ac.uk/shm/dhr/research/ healthandplace/fmdfinalreport.pdf. Accessed 4 Jan 2010

Moser SC (2010) Communicating climate change: history, challenges, process and future directions. WIREs Clim Chang 1(1):31-53

Neria Y, Nandi A, Galea S (2008) Post-traumatic stress disorder following disasters: a systematic review. Psychol Med 38:467-480

O'Neill P (2004) Developing a risk communication model to encourage community safety from natural hazards. Available from http://www.ses.nsw.gov.au/papers/oneill_2004b.pdf (Accessed 5th November 2011)

Parker D, Tapsell S, McCarthy S (2007) Enhancing the human benefits of flood warnings. Nat Hazards 43:397-414

Parker DJ, Priest SJ, Tapsell SM (2009) Understanding and enhancing the public's behavioural response to flood warning information. Meteorol Appl 16:103-114

Pearlin LI, Schooler C (1978) The structure of coping. J Health Soc Behav 19(1):2-21

Powell MC, Colin M (2009) Participatory paradoxes: facilitating citizen engagement in science and technology from the top-down? Bull Sci Technol Soc 29:325-342

Reich JW, Zautra AJ (1990) Dispositional control beliefs and the consequences of a control-enhancing intervention. J Gerontol 45(2):46-51 
Renn O (2005) White paper on RISK GOVERNANCE: towards an integrative approach. International risk governance council, Geneva

Renn O (2008) Risk governance: coping with uncertainty in a complex world. Earthscan, London

Rogers EM, Kincaid DL (1981) Communication networks: towards a new paradigm for research. Free Press, New York

Rohrmann B (1998) Assessing hazard information/communication programs. Aust Psychol 33(2):105-112

Rowan KE (1994) The technical and democratic approaches to risk situations: their appeal, limitations, and rhetorical alternative. Argumentation 8:391-409

Rowe C, Liddle HA (2008) When the levee breaks: treating adolescents and families in the aftermath of Hurricane Katrina. J Marital Fam Ther 34(2):132-148

Scolobig A, Castan Broto V, Zabala A (2008) Integrating multiple perspectives in social multicriteria evaluation of flood-mitigation alternatives: the case of Marlborghetto-Valbruna. Envrion Plan C Gov Policy 26:1143-1163

Slovic P (1993) Perceived risk, trust, and democracy. Risk Anal 13(6):675-682

Spence A, Pidgeon N (2010) Framing and communicating climate change: the effects of distance and outcome frame manipulations. Glob Environ Chang 20(4):656-667

Stanghellini PSL, Collentine D (2008) Stakeholder discourse and water management: implementation of the participatory model $\mathrm{CATCH}$ in a Northern Italian alpine sub-catchment. Hydrol Earth Syst Sci 12:317-331

UN/ISDR (2006) Hyogo framework for action 2005-2015: building the resilience of nations and communities to disasters. World conference on disaster reduction. Extract from the final report of the world conference on disaster reduction, 18-22 January 2005, Kobe, Hyogo, Japan. UN/ISDR, Geneva

Uskul AK, Oysermann D (2010) When message-frame fits salient cultural-frame, messages feel more persuasive. Psychol Health 25(3):321-337

Walker G, Whittle R, Medd W, Watson N (2010a) Risk governance and natural hazards. CapHaz-Net WP2, D2.1 as of 16/4/2010. Lancaster University, Lancaster Environment Centre, Lancaster. Available from http://caphaz-net.org/outcomes-results/CapHaz-Net_WP2_Risk-Governance2.pdf. Accessed 5 May 2010

Walker M, Whittle R, Medd W, Burningham K, Moran-Ellis J, Tapsell S (2010b) Children and young people after the rain has gone: learning lessons for flood recovery and resilience. Lancaster University, Lancaster. Available from http://www.lec.lancs.ac.uk/cswm/Hull\%20Children's\%20Flood\%20Project/ FINAL\%20REPORT.pdf (Accessed 1st April 2011)

Weiss K, Girandola F, Colbeau-Justin L (2010) Les comportements de protection face aux risques naturels: de la résistence à l'engagement. Pratiques psychologiques. Available from http://www.emconsulte.com/article/247836. Accessed 1 April 2011

Whittle R, Medd W, Deeming H, Kashefi E, Mort M, Twigger-Ross C, Walker G, Watson N (2010) After the rain-learning the lessons from flood recovery in Hull. Final project report for Flood, Vulnerability and Urban Resilience: a real-time study of local revovery following the floods of June 2007 in Hull. Lancaster University. Available from Lancaster http://www.cila.co.uk/files/AFTER\%20THE\% 20RAIN\%20FULL\%20REPORT.pdf. Accessed 1 April 2011

Zautra AJ, Hall JS, Murray KE (2008) Resilience: a new integrative approach to health and mental health research. Health Psychol Rev 2(1):41-64 